\title{
USING EVERYDAY LANGUAGE TO SUPPORT LEARNERS’'ACCESS TO MATHEMATICAL CONTENT KNOWLEDGE
}

\author{
Azwidowi Emmanuel Libusha \\ Department of Childhood Education, University of Johannesburg (South Africa)
}

\begin{abstract}
The language of mathematics can hinder the development of some learners' conceptual understanding of mathematics. Language as a whole plays a crucial role in the teaching and learning of mathematics as it serves as the medium in which the teachers and learners think and communicate in the classroom. Ball, Thames and Phelps (2008) argue that the demands of teaching mathematics require specialized mathematical knowledge that only pertains to mathematics teaching and is not required in other mathematics professions. The role of the teacher is to use resources available to them to support learners in accessing mathematical content knowledge. Previous researchers acknowledged the difficulty learners face when trying to interpret the formal language of mathematics in order to access mathematical content knowledge. Consequently, the current study explored the various ways in which the language of learning and teaching can be utilized by teachers to mitigate language difficulties their learners may experience. The study was guided by the research question: What is the informal mathematical language that Grade 10 teachers use to inform effective instruction when teaching functions? This paper aims to describe how teachers use informal mathematical language to teach inequalities and functions. The research is qualitative and the descriptive method was employed, with the researcher serving as the main instrument. The required data was collected by observing two teachers teaching inequalities and functions. The findings indicate that the use of transliteration and demonstrations as teaching strategies reduced the challenges of using English as a medium of instruction to interpret mathematical symbolic language and that the use of everyday language makes a difference in the learning of functions and inequalities. The study informs both pre-service and in-service teacher development programmes.
\end{abstract}

Keywords: Mathematics, mathematical language, teacher practice, functions, inequalities.

\section{Introduction}

Teaching mathematics effectively depends on how well the teacher can communicate mathematical concepts. According to Lampert and Cobb (2003), communication and language are the most basic elements that are involved in the teaching and learning of mathematics. The content knowledge possessed by the teacher and how the teacher communicates that knowledge using a particular language are vital when learners are learning mathematics. A study by Nomlomo (2010) revealed that learners struggle to access mathematical content knowledge because of a failure to understand the language of learning and teaching. The language of learning and teaching needs to be made simpler and accessible in order for learners to understand what is being communicated to them.

The Curriculum and Assessment Policy Statement (CAPS) (Department of Basic Education, 2011) defines mathematics as a language that makes use of symbols and notations to describe numerical, geometric and graphical relationships. This implies that understanding the language of mathematics is the key ingredient in supporting learners to access mathematical content knowledge. How well learners understand the language of learning and teaching depends on their background and the environment in which they live. To some, English is their second language and they do not use it at home; to some it is their first language and to others it is a language they are still learning. It is imperative that both teachers and learners communicate at the same level while learners progress to a higher level of mathematics influenced by the mathematical language required for that particular level. De Villiers (2010) argues that learners struggle with mathematics because teachers teach it using language that is above the level of the learners.

This paper seeks to determine the language used by teachers to teach to teach the section on functions of mathematics in the curriculum effectively. This study draws from Pimm's (1991) hypothesis that good teaching entails extensive subject matter knowledge and an understanding of alternative ways 
of presenting such knowledge to learners using language. The study was guided by the research question: What is the informal mathematical language that Grade 10 teachers use to inform effective instruction when teaching functions? The paper aims to describe how teachers use informal mathematical language to teach inequalities and functions.

\section{Literature review}

Clarkson (2009) discusses globalization and how it has affected the way mathematics is being taught in different countries. Due to globalization, language affects the teaching of mathematics in the multilingual classroom. In an ideal classroom, learners are assumed to be proficient in the language of learning and teaching and their proficiency should not affect how they learn mathematics. However, when the language of learning and teaching is not the learners' first language, the way in which mathematics is communicated and understood in the classroom is affected.

Clarkson (2009) argues that the first language of the teacher and that of the learners together with the common language that is used in a normal conversation, which may not be the official teaching language, must be considered in the mathematics classroom when learners are communicating about mathematical ideas. While the mathematics used at a high school level and primary school level is not synonymous with the mathematics used in other domains of practice such as engineering, one has to understand that the mathematics taught by teachers in school classrooms is critically important (Adler, 2005), because a firm understanding of this level of mathematics opens doors for the mathematics used in other professions.

In Johannesburg, where the study was conducted, one usually finds multilingual teachers teaching multilingual students in English, which is not the first language of the teacher or of most students in the classroom (Hooijer \& Fourie, 2009). For example, you may find learners who are fluent in English but not fluent in mathematical English. In this instance, learners must first communicate their mathematical understanding in plain English and so develop mathematical English before they can understand the mathematical content knowledge. Tikunoff (1985) asserts that learners learn most effectively in the language they understand the best. However, sometimes the language that learners understand the best is not their first language but rather the local street language combined with slang. As a result, learners are encouraged to use the language they know or their daily language to communicate their mathematical ideas. Once they understand informal mathematical language, it will lead them to understand formal mathematical language, and they will be in a position to do mathematics.

\section{Theoretical framework}

The study used code switching as a learning resource or a mechanism for learning that teachers can use to enable learners to gain access to the mathematical content or the language of mathematics. The language teachers use to support learners, the method of teaching (pedagogical content knowledge) and the knowledge of how to bridge the gap between the language of learning and teaching (English), mathematical language and the mathematical content knowledge constitute specialized subject knowledge that a teacher should possess (Adler, 2006; Ball \& Bass, 2000; Shulman, 1986). The researcher adopted Pimm's (1981) notion of the importance of understanding the mathematical register. According to Pimm (1981), the aim of mathematical language or register is to help construct, express and communicate mathematical meanings, because when written mathematics is understood and mathematical terms or the register is well understood, it will enable a learner to make sense of mathematical concepts.

\section{Methodology}

The description is based on the qualitative research method. The required data was collected by observing two teachers teaching inequalities and functions. The research is qualitative; the method is descriptive and the researcher is the main instrument of this research.

\subsection{Selection of participants}

Using the purposive sampling technique, two mathematics teachers from the same school in Gauteng province were selected. The purposive sampling is when researchers thoroughly think through how they will establish a sample population, even if it is not statistically representative of the greater population at hand (Creswell, 2005). These teachers had taught Grade 10 mathematics for more than five years and mathematical functions is one of the topics included in the curriculum. Within five years of teaching functions, teachers should have developed and established the competency to teach the topic. 
Teacher A was a white woman and English was her first language; Teacher B was an African male and English was not his first language.

\subsection{Data collection and analysis}

Two methods of data collection were used to ensure methodological triangulation (Creswell, 2005). The non-participant observation method was appropriate as it allowed the researcher to observe the teachers" practices in "real life" classroom contexts (Golafshani, 2003). Each teacher was interviewed once using a semi-structured interview schedule to gain clarity on the issues the researcher did not understand during classroom observations and also to determine their conceptual understanding of range and domain when doing functions. The data analysis involved descriptive coding of data from interviews and lesson observations using Henning, Gravett and Van Rensburg's (2005) manual.

\section{Findings}

\subsection{Teacher A}

During the interview, the teacher was asked how she would explain the concepts of range and domain to someone who is hearing the terms for the first time. Teacher A defined a domain as "looking at the space the function covers from left to right focusing on the x-axis, and the range is looking at the space the function covers from the bottom to the top focusing on the y-axis."

During the classroom observation, Teacher A explained the effect of a on the graph of hyperbolas that have the equation $\mathrm{y}=\mathrm{a} / \mathrm{x}$. The teacher explained how to determine the range and domain when the value of a is greater than zero. The teacher started by explaining that the value of a determines the space the function will occupy on the Cartesian plane. The teacher pointed on the graph that was drawn on the board and explained to the learners that when the value of a is positive, the graph will curve towards the top right corner and bottom left corner (see Figure 1). This means the functions will occupy the first and third quadrants of the Cartesian plane.

\section{Figure 1. $f(x)=a / x$ when the value of a is positive.}

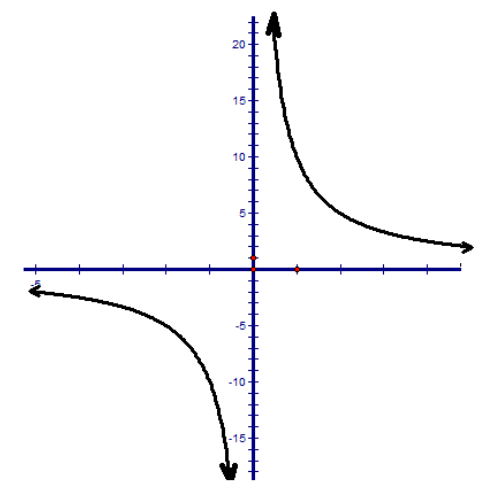

The teacher proceeded to explain that when looking at the function from left to right, the function will start from negative infinity and curve towards the $y$-axis and from the $y$-axis to positive infinity; looking at the function from the bottom to the top, the function will start from negative infinity and move towards the $x$-axis and from the $x$-axis to positive infinity. Teacher $\mathrm{A}$ then explained the concept using informal mathematical language and included mathematical terms. Thereafter, Teacher A explained that when $a$ is greater than 0 , the domain of the graph will be greater than zero and less than zero with a range that is greater than zero and less than zero. The last part of the explanation incorporated mathematical symbolic language as she wrote the statement in symbolic form for the students: for example, when $a>0$, then $0<x<0$ and $0<y<0$.

\subsection{Teacher B}

During the interview, Teacher B explained the range and domain as follows: "The domain is the $\mathrm{x}$-values and the range is the $\mathrm{y}$-values; basically, finding the range and domain is all about finding all the $\mathrm{x}$-values and all the $\mathrm{y}$-values when a function is given."

During the classroom observation, Teacher B started by explaining the domain and range using the concept of inputs and outputs when drawing a function using the table method. Based on the teacher's explanation, the inputs are the x-values, which are the domain, and the outputs are the $y$-values, which are the range. Teacher $\mathrm{B}$ explained that regardless of how many $\mathrm{x}$-values you take, you will always get the corresponding $\mathrm{y}$-values. Teacher $\mathrm{B}$ then reminded the learners of continuous functions and discontinuous 
functions. Drawing from the understanding of discontinuous functions, the concept of the asymptote was explained. Based on this concept, the domain and range were explained using the table method and learners were instructed to also use a zero, which gave an undefined answer. The teacher then said the function was not continuous because it was undefined when the value of $\mathrm{x}$ was zero. He then said that the domain is represented by the set of real numbers except when $\mathrm{x}$ is equal to zero.

\section{Discussions}

Nomlomo (2010) writes about the progression from informal language to formal mathematical language in a situation where learners are either bilingual or multilingual. She argues that teachers must be in a position to move learners from predominantly informal spoken language - the kind that learners use in their everyday life to express mathematical thinking-to formal written mathematical language. Teacher A managed to do this. To understand how to interpret the symbolic form, one has to move from everyday English to formal mathematical English and understand how mathematical English can be transformed into symbols. In Teacher A's class, the use of common language or the language used to explain mathematical terms can be regarded as informal mathematical language. For example, consider the teacher's explanation: "when looking at the function from left to right, the function will start from negative infinity to the y-axis without touching the y-axis and from the y-axis to positive infinity and looking at the function from the bottom to the top, the function will start from negative infinity to $\mathrm{x}$-axis without touching the $\mathrm{x}$-axis and from the $\mathrm{x}$-axis to the positive infinity."

The statement above can be regarded as informal mathematical language. However, in formal mathematical language, one would say the following: if the value of a is less than zero, the graph will possess a maximum turning point and if the value of a is greater than zero the graph will possess a minimum turning point. The difference between the two sentences is that the one has mathematical terms and the other one has English terms used on a daily basis. Look at the following words:

Table 1. English language vs mathematical language.

\begin{tabular}{|l|l|l|}
\hline To the right & - & Positive infinity \\
\hline From the left & - & Negative infinity \\
\hline $\begin{array}{l}\text { From } x \text {-axis without } \\
\text { touching the } x \text {-axis }\end{array}$ & - & Greater than zero \\
\hline $\begin{array}{l}\text { To the } x \text {-axis without } \\
\text { touching the } x \text {-axis }\end{array}$ & - & Less than zero \\
\hline
\end{tabular}

Even though the statements on the left and those on the right are both in English, there is a difference in the usage. Learners can be encouraged to move between the three forms of language. They can move from informal language to mathematical language, and then progress from formal mathematical language to symbolic mathematical language. This will be easier if the informal language is the language of learning and teaching compared to a different language, because informal mathematical language will contain mostly English words. Understanding the language of learning and teaching in the context of a learner's daily language can make a difference in how a learner understands mathematical content knowledge (Setati, 2006).

In his lesson, Teacher $\mathrm{B}$ focused on mathematical language. For a learner to be able to understand Teacher B, their understanding of the mathematical register must be intact. Teacher B used formal mathematical language to get learners to access mathematical content knowledge, which in this case was to understand the domain and the range of the hyperbola function. Although the teaching approaches differed, both teachers did get the message across. The only challenge would be the audience the lesson is intended for: learners who have a good understanding of the mathematics register or learners who are still learning the register. As Pimm (1991) points out, the teacher should realise that part of learning mathematics is gaining control over the language of mathematics so that one is able to communicate mathematics-related concepts with fluency and understanding. However, mathematics as a subject is difficult enough as it is, and failing to understand the language of mathematics can result in failing to understand the mathematical content knowledge.

\section{Conclusion}

The study explored the various ways in which the language of learning and teaching can be utilized by teachers to mitigate language difficulties their learners experience when learning mathematical functions in Grade 10. The findings indicate that the use of transliteration and demonstrations as teaching strategies reduced the challenges of using English as a medium of instruction to interpret mathematical 
symbolic language and that the use of everyday language makes a difference in the learning of functions and inequalities.

Although both teachers have an understanding of the mathematical content, using everyday English words, as illustrated by Teacher A, enabled some of the learners to understand the mathematical content knowledge. This was recognized by the responses learners gave when asked to provide explanations on the board. The use of mathematical terms without explaining them thoroughly with the use of everyday language has caused learners to lack confidence in the mathematics classroom. This was observed when there were no learners willing to explain their own understanding. This study concludes that the use of everyday language or common language plays an important role in the teaching of mathematics. The common language is a resource that can be used to inform effective instruction when teaching mathematical inequalities and functions.

\section{References}

Adler, J. (2005). Mathematics for teaching: What is it and why is it important that we talk about it? Pythagoras, 62, 2-11. doi:10.4102/pythagoras.v0i62.109

Adler, J. B. (2006). Teaching mathematics in multilingual classrooms (Vol. 26). Cham: Springer.

Ball, D. L., \& Bass, H. (2000). Interweaving content and pedagogy in teaching and learning to teach: Knowing and using mathematics. In J. Boaler (Ed.), Multiple perspectives on the teaching and learning of mathematics (pp. 83-104). Westport, CT: Ablex.

Ball, D. L., Thames, M. H., \& Phelps, G. (2008). Content knowledge for teaching: What makes it special? Journal of Teacher Education, 59(5), 389-407. doi:10.1177/0022487108324554

Clarkson, P. C. (2009). Potential lessons for teaching in multilingual mathematics classrooms in Australia and Southeast Asia. Journal of Science and Mathematics Education in Southeast Asia, 32(1), 1-17.

Creswell, J. W. (2005). Educational research: Planning, conducting, and evaluating quantitative and qualitative research (2nd ed.). Upper Saddle River, NJ: Pearson Education.

De Villiers, M. (2010, June). Some reflections on the Van Hiele theory. Paper presented at the 4th congress of teachers of mathematics of the Croatian Mathematical Society, Zagreb. Retrieved from https://www.researchgate.net/publication/264495589_Some_Reflections_on_the_Van_Hiele_ theory

Department of Basic Education. (2011). Curriculum and assessment policy statement: Life sciences; Further education and training phase Grade 10-12. Pretoria: Author.

Golafshani, N. (2003). Understanding reliability and validity in qualitative research. The qualitative report, 8(4), 597-607.

Henning, E., Gravett, S., \& Van Rensburg, W. (2005). Finding your way in academic writing. Pretoria: Van Schaik Publishers.

Hooijer, E., \& Fourie, J. (2009). Teacher's perspective of multilingual classrooms in a South African school. Education as Change, 13(1), 135-151. doi:10.1080/16823200902943304

Lampert, M., \& Cobb, P. (2003). Communication and language. In J. Kilpatrick, W. G. Martin, \& D. Schifter (Eds.), A research companion to principles and standards for school mathematics (pp. 237-249). Reston, VA: National Council of Teachers of Mathematics.

Nomlomo, V. (2010). Classroom interaction: Turn-taking as a pedagogical strategy. Per Linguam: A Journal of Language Learning / Tydskrif vir Taalaanleer, 26(2), 50-66. doi:10.5785/26-2-21

Pimm, D. (1981). Metaphor and analogy in mathematics. For the Learning of Mathematics, 1(3), 47-50.

Pimm, D. (1991). Communicating mathematically. In K. Durkin \& B. Shire (Eds.), Language in mathematical education (pp. 17-23). Milton Keynes: Open University Press.

Setati, M. (2006). Access to mathematics versus access to the language of power. In J. Novotná, H. Moraová, M. Krátká, \& N. Stehlíková (Eds.), Proceedings of the 30th Conference of the International Group for the Psychology of Mathematics Education (Vol. 5, pp. 97-104). Prague: PME.

Shulman, L. S. (1986a). Those who understand: Knowledge growth in teaching. Educational researcher, 15(2), 4-14. doi:10.3102/0013189X015002004

Shulman, L. S. (1986b). Those who understand: A conception of teacher knowledge. American Educator, $10(1), 9-15$.

Tikunoff, W. J. (1985). Developing student functional proficiency for LEP students. Portland, OR: Northwest Regional Educational Laboratory. 